\title{
2019 newly elevated Fellows of the International Sol-Gel Society
}

\section{Kiyofumi Katagiri ${ }^{1}$}

Published online: 30 March 2020

(c) Springer Science+Business Media, LLC, part of Springer Nature 2020

In 2018, the International Sol-Gel Society (ISGS) launched the Fellowship Program to recognize members of the ISGS who have made outstanding contributions to the sol-gel sciences and technology through broad and productive scholarship in sol-gel science and technology, by conspicuous achievement in sol-gel industry, or by outstanding service to the ISGS. The Fellows of the ISGS shall be persons of good reputation who have reached their 45th birthday and who have been members of the ISGS at least four years continuously. This Fellowship is a distinct honor signifying recognition by one's professional peers. First, all of the previous ISGS Life Achievement Awardees have been certified as Fellows. After that, every two years, no more than $1 \%$ of the total number of ISGS members can be recognized by their peers for election to the grade of Fellow of the ISGS. The candidates are nominated by at least one current Fellow and three additional regular members. All nomination materials are forwarded in confidence to the Board of Directors of ISGS. The successful candidates are elevated to the grade of Fellow and celebrated during the International Sol-Gel Conference.

The nomination process for the 2019 edition of the Fellows of ISGS was opened on December 31, 2018. After the deliberations and voting, the Board of Directors of ISGS decided that three candidates could be elevated as the 2019 ISGS Fellows:

Dr. Rui Almeida, a Professor in the Departamento de Engenharia Quimica of the Instituto Superior Técnico, Lisbon, Portugal,

Dr. Kazuki Nakanishi, a Professor in the Institute of Materials and Systems for Sustainability, Nagoya University, Nagoya, Japan, and

Kiyofumi Katagiri

kktgr@hiroshima-u.ac.jp

1 Graduate School of Advanced Engineering and Science, Hiroshima University, 1-4-1 Kagamiyama, HigashiHiroshima 739-8527, Japan
Dr. Galo Juan de Avila Arturo Soler-Illia, a Professor in the Instituto de Nanosistemas, Universidad Nacional de General San Martín, Buenos Aires, Argentina.

Dr. Rui Almeida (Fig. 1) was born in 1952 and received his Master of Sciences (1978) and Ph.D. in Materials Engineering (1980) degrees from the University of California, Los Angeles, where Prof. John D. Mackenzie advised his dissertation. He then got his aggregation at the Instituto Superior Técnico (IST) in 1987. In 1990, he was promoted to a full professor (Catedrático) at the IST and has been President of the Department of Materials Engineering from 2000 to 2004, and Scientific Coordinator of the Instituto de Ciência e Engenharia de Materiais e Superficies in 1996-2002 and 2007-2010. He is also a senior member of the Ordem dos Engenheiros of Portugal. $\mathrm{He}$ is presently an associate editor of the International Journal of Applied Glass Science, and member of the Editorial Advisory Board of several journals, including Journal of Sol-Gel Science and Technology and Journal of Non-Crystalline Solids. He has also served as member of the Board of Directors of ISGS for 6 years (2009-2015). His main interests are the structural and optical properties of glasses, such as chlorophosphate, fluorozirconate, and fluorohafnate glasses, and sol-gel derived thin films, as well as photonic crystal-assisted frequency conversion materials and structures for application in energy and white-light generation.

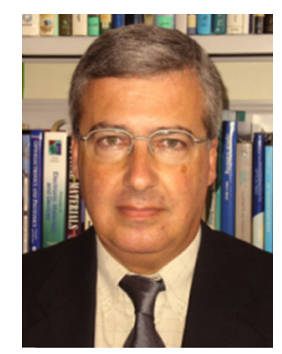

Fig. 1 Dr. Rui Almeida 


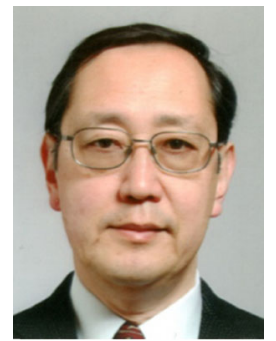

Fig. 2 Dr. Kazuki Nakanishi

Dr. Kazuki Nakanishi (Fig. 2) was born on January 22, 1961 and received his Bachelor (1983), Master (1985), and Doctor of Engineering (1991) degrees from Kyoto University, Japan. He started his research on transport phenomena of small molecules in polymer solids in his graduate course at the Institute for Chemical Research, Kyoto University. In the middle of his Ph.D. course, he was appointed as a research associate at the Inorganic Structural Chemistry group at the Faculty of Engineering, Kyoto University (Prof. Naohiro Soga) and started working in the field of sol-gel processing in 1986. His pioneering works on "hierarchically porous monolithic materials via sol-gel process accompanied by phase separation" opened a new era of integrating micro/mesoporous structures into those with highly efficient liquid-solid contact. As a result, monolithic liquid chromatography columns proved by far superior to the conventional counterpart, columns with particle-packed structure, and were successfully commercialized. He continued extending the chemical composition of porous monoliths prepared by similar processes, and a wide range of oxides, hydroxides, phosphates, and silsesquioxanes have been proven to constitute well-defined macroporous structures. Recent achievements of his group include "ambient dried large-sized organic-inorganic hybrid aerogels," "highly efficient surface modification using hydrosilanes," and "hierarchically porous monoliths for flow through catalysis/separation". In recent works, additional kinds of chemical/physical interaction have been introduced. Aerogels based on alkylsilsesquioxane network have been developed using kinetic structural regulation of polycondensation of trifunctional silanes by surfactants and base catalysts. Controlled precipitation of metal organic frameworks (MOFs) onto the pore surfaces of well-defined macroporous metal oxide/hydroxide will be a novel method of 3D structuring of MOFs by solid-state ligand exchange (catalyst/adsorbent). All these materials are to be explored for practically useful applications. Dr. Nakanishi has also been active in encouraging young students and emerging researchers to build up their career through giving them exciting research opportunities. His contacts with

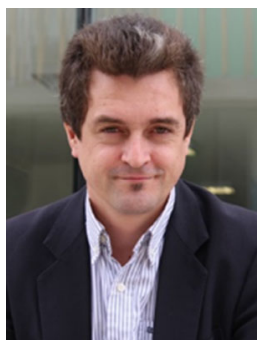

Fig. 3 Dr. Galo J.A.A. Soler-Illia

researchers and institutes abroad are accumulated to more than 60 universities/institutes/companies in $>25$ nations/ regions worldwide. His service in the Sol-Gel community is widespread and long. He served as Board Member and Vice President both in ISGS and the Japanese Sol-Gel Society (currently President). He serves as one of the five co-editors of Journal of Sol-Gel Science and Technology. In addition, he chaired the 18th International Sol-Gel Conference which was held in Kyoto in 2015.

Dr. Galo J.A.A. Soler-Illia (Fig. 3) was born in May 31, 1970 and received his Ph.D. degree in Chemistry from Buenos Aires University (1998). He spent several years as a postdoctoral research fellow at Université Paris VI, France under the supervision of Prof. Clément Sanchez. Currently, he is the dean of Instituto de Nanosistemas, Universidad Nacional de General San Martín. He has made an outstanding and sustained contribution to materials chemistry, particularly in the understanding of the formation processes of nanomaterials. He took advantage of a variety of synthetic tools that include sol-gel chemistry, self-assembly, surface modification, and local reactivity techniques to obtain highly controlled nanomaterials with finely tuned inorganic framework, pore size, shape, controlled surface area, and pore volume. By combining these nanometric building blocks, he has obtained complex nanosystems, in which the properties stem from the actual functions but also from their relative position in space, in a similar fashion to what is obtained in natural systems. The techniques generated in his group are now being transferred to industry, in several collaboration projects. The impact of his work has been recognized by more than 10,000 citations (h-index $=$ 49), invitation to more than 50 national and international conferences, and is being invited to publish reviews and feature articles in renowned journals. In addition, he has supervised a number of young researchers, including more than $30 \mathrm{Ph} . \mathrm{D}$. students and postdoctoral fellows. Through these activities, he has built networks of collaboration within Argentina and with International Laboratories. He has also organized the biannual Buenos Aires Sol-Gel School since 2003. He has received several national awards 
including two Houssay Prizes (2006, 2010), ANCEFN and ANC prizes, the Konex Platinum Award in Nanotechnology, 2013, and the INNOVAR Great Prize 2016.

On August 29, 2019, the ISGS Fellow Ceremony took place during The XX International Sol-Gel Conference held in St. Petersburg, Russia, to mark their meritorious achievement (Fig. 4).

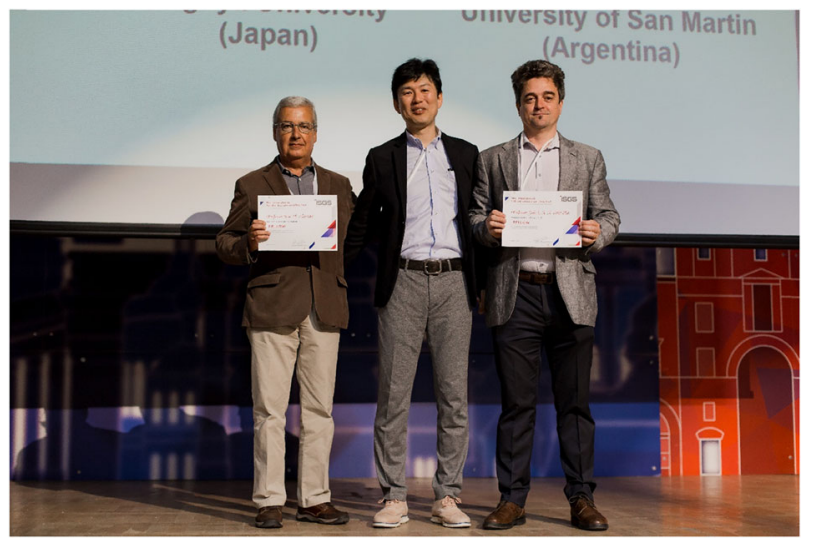

Fig. 4 Prof. Almeida (left) and Prof. Soler-Illia (right) receiving the diplomas for ISGS Fellow from Prof. Masahide Takahashi (center), the President of ISGS 